九州大学学術情報リポジトリ

Kyushu University Institutional Repository

\title{
Structural Integrity Study for a Quadcopter Frame to Be Deployed for Pest Control
}

Ibrahim, Sulaiman

Department of Mechanical Engineering, Federal University of Technology Minna

Alkali, Babawuya

Department of Mechatronics Engineering, Federal University of Technology Minna

Oyewole, Adedipe

Department of Mechanical Engineering, Federal University of Technology Minna

Salihu Bala Alhaji

Department of Telecommunication Engineering, Federal University of Technology Minna

他

https://doi.org/10.5109/4491843

出版情報：Evergreen. 8 (3)，pp.667-672，2021-09. 九州大学グリーンテクノロジー研究教育センター バージョン：

権利関係 : 


\title{
Structural Integrity Study for a Quadcopter Frame to Be Deployed for Pest Control
}

\author{
Sulaiman Ibrahim ${ }^{1 *}$, Babawuya Alkali ${ }^{2}$, Adedipe Oyewole ${ }^{1}$, Salihu Bala Alhaji ${ }^{3}$, \\ Aliyu Alhaji Abdullahi ${ }^{1}$, Ibrahim Aku G. ${ }^{4}$ \\ ${ }^{1}$ Department of Mechanical Engineering, Federal University of Technology Minna, Nigeria \\ ${ }^{2)}$ Department of Mechatronics Engineering, Federal University of Technology Minna, Nigeria \\ ${ }^{3}$ Department of Telecommunication Engineering, Federal University of Technology Minna, Nigeria \\ ${ }^{4}$ Department of Physics, Federal University of Technology Minna, Nigeria \\ *Author to whom correspondence should be addressed: \\ E-mail: skishk2009@gmail.com
}

(Received January 7, 2021; Revised September 6, 2021; accepted September 6, 2021).

\begin{abstract}
Quadcopters are one of the most versatile unmanned aerial vehicles deployed for various purposes. In this study it is going to be used as part of a system used for bird control therefore the structural integrity is investigated. The aim of the paper is to investigate the structural and aerodynamic behaviour of a quadcopter intended for bird control. A model of the drone has been developed in SolidWorks, then structural along with flow analysis carried out using ANSYS software. The structural analysis reveals a maximum stress of $39.13 \mathrm{MPa}$ of the arm due to thrust and 2.6 MPa on the frame due to load which are within the safe range for use of purpose.
\end{abstract}

Keywords: Bird control; computational fluid dynamics; structural analysis; surveillance; unmanned aerial vehicles

\section{Introduction}

Birds are one the most destructive to cereal farms in Nigeria and their control is of significant concern. Various studies have introduced the use of aerial devices for pest control to varying degrees of success. It may be the most effective method of controlling bird population in farms ${ }^{1}$. The use of quadcopters has become popular in recent years due to its high manoeuvrability and simple design ${ }^{2}$. It is used by hobbyists, in military, agriculture, service delivery and relief applications. Carrying sufficient weight for some of these applications is of interest particularly for agricultural, relief and service delivery purposes. Investigating the effect of weight on the mechanical structure of the unmanned aerial vehicle (UAV) is important.

Finite Element Analysis (FEA) software is an easy way these investigations can be conducted at almost no cost. Using FEA software reduces overall time in the design process. They allow various operational conditions to be modelled, analysed and the design enhanced by providing a more standardised iterative process ${ }^{3), 4)}$. A 3D model is often used for the investigation and the necessary boundary conditions applied to the model for analysis.

Software like SolidWorks is used to model the drone and investigation regarding the structure and computational fluid dynamics (CFD) analysis conducted in ANSYS software as provided in different literature ${ }^{2), 4), 5)}$.
Investigating the load effect on the mechanical structure of the drone may require static structural or transient analysis. This will highlight the stresses that are present in the structure along with the deformations and strains. The CFD on the other hand reveals the effects of wind acting on the quadcopter structure. ANSYS Fluent or CFX (high performance CFD solver) are used in ANSYS workbench. Some of the parameters obtained from flow simulation are the wind pressure, lift and drag forces acting on the quadcopter surface ${ }^{6), 7)}$.

Both studies (Structural FEA and CFD analyses) follow the same procedure of first discretising the structure studied into thousands to millions of elements and solving for each element using the suitable governing equations, and then assembling the results thereafter ${ }^{8), 910)}$.

Singh et al. ${ }^{2}$ studied the static and dynamic characteristics of a UAV frame and obtained a maximum stress of $6.27 \mathrm{MPa}$ and deformation of $5.84 \mathrm{~mm}$ for the static structural analysis. The stress reducing for the dynamic analysis of the same structure to $0.23 \mathrm{MPa}$. The study employed ANSYS workbench for their finite element analysis. Most of the stresses were recorded across the edges of the UAV arms.

Kuantama et al.5) used SolidWorks design software to model and carryout finite element study on a quadcopter structure. The study investigated the effect of thrust on the quadcopter arm and the propeller and rotor's angular 
velocity and air flow produced around the propeller. Results of the study revealed the possibility of flight instability or high vibrations due to rotational velocities of propellers selected for the set up.

Ahmed et al.6) modelled and analysed the frame of the F450 quadcopter. The model was developed using AutoCAD software and analysis in ANSYS Workbench. The study examined the upper and bottom plates separately then the complete assembled frame. The maximum equivalent stress obtained on the top plate was 2.25 and 23.0 MPa on the frame assembly when the load was applied.

Felismina et al. ${ }^{11)}$ studied the aerodynamic behaviour of a UAV with an applied seeder for agricultural practices. A suitable inclination during operation was sought by the study to allow for better battery live economy. The study concluded that the $30^{\circ}$ was most suitable for take-off while the $0^{\circ}$ was most suitable for operations.

Al-zogphy et al. ${ }^{12}$ ) studied the impact of airflow on quadcopter frame to ascertain if the frame is suitable and rigid enough to afford components weight. The geometry was created using Autodesk Inventor 2017. The frame material considered for the analysis was PLA-PLUS and executed by 3Dprinting machine afterwards. The maximum elastic stress was determined to be $1.1498 \mathrm{MPa}$ while the strain was 0.0011151 . The stresses were observed on the extreme edges of the frame.

The model intended for investigation when imported to the ANSYS workbench must have sufficient boundary conditions defined. Those conditions are derived from the actual conditions in the real world. The thrusts, wind, modal and weight effects may be investigated as required $^{13)}$. The basic steps followed are choosing the type of study, applying a suitable mesh on the geometry, applying the boundary conditions and finally running the analysis $^{13), 14), 15), 16)}$.

The objective of this study is to carryout structural and CFD analyses on a F450 quadcopter frame to ascertain the suitability for deployment in a pest control system. The quadcopter is to deter pest by broadcasting selected sounds and intermittent spraying. The study will investigate the effect of the load on the structure and ascertain if the selected frame is suitable for the system.

\section{Methodology}

The method is adopted from previous literature ${ }^{1), 17)}$. The model is selected, modelled and analysed as represented in Fig. 1.

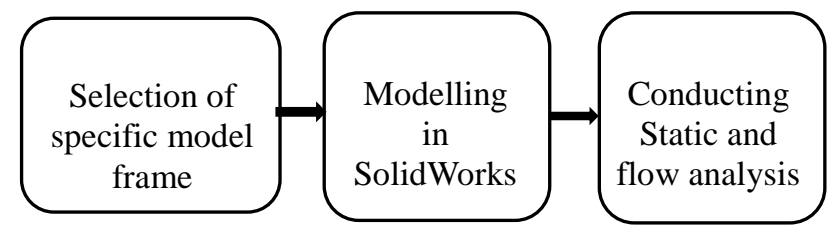

Fig. 1: Methodology block diagram

DJI F450 quadcopter frame structure is used for this analysis ${ }^{2}$. The model is created in SolidWorks 2020 with dimensions obtained from product user manual and other literature $^{5)}$. The total loads the UAV will carry was determined likewise and represented in Table 1.

Table 1. Weight estimation

\begin{tabular}{|l|l|c|l|}
\hline S/N & Components & Quantity & Mass (kg) \\
\hline 1. & Frame & 1 & 0.312 \\
\hline 2. & Propeller & 4 & 0.052 \\
\hline 3. & Motor & 4 & 0.208 \\
\hline 4. & $\begin{array}{c}\text { Electronic speed } \\
\text { controllers (ESC) }\end{array}$ & 4 & 0.108 \\
\hline 5. & Battery & 1 & 0.320 \\
\hline 6. & GPS module & 1 & 0.025 \\
\hline 7. & Flight controller & 1 & 0.050 \\
\hline 8. & Camera & 1 & 0.028 \\
\hline 9. & Micro pump & 1 & 0.113 \\
\hline 10. & Liquid & 1 & 0.200 \\
\hline 11. & Mp3 player & 1 & 0.200 \\
\hline & Total & & 1.616 \\
\hline
\end{tabular}

The frame mass is obtained using SolidWorks mass property function. The total weight $W_{t}$ is obtained using Eq. $1^{8)}$.

$$
\mathrm{W}_{\mathrm{t}}=\mathrm{W}_{\mathrm{E}}+\mathrm{W}_{\mathrm{P}}
$$

Where, $\mathrm{W}_{\mathrm{E}}$ is the empty weight in Newton $(\mathrm{N})$ and $\mathrm{W}_{\mathrm{P}}$ is the payload weight in N. The empty load includes the frame, battery, electronic speed controllers (ESCs) and motor weights while the payload are additional weights on the frame. Weight acting directly on the upper plate is determined as $9.2 \mathrm{~N}$, this is the weight that directly acts on the plate. It includes the weight of the components listed in Table 1 except for the frame, propellers, motors and the Electronic speed controllers (ESC). The mass is determined as $0.936 \mathrm{~kg}$, and is converted to weight by multiplying with acceleration due to gravity.

$$
0.936 \times 9.81=9.18 \mathrm{~N}
$$

The required thrust $\mathrm{Th}_{\mathrm{r}}$ in $\mathrm{N}$, is the minimum thrust that will be able to lift the total UAV weight. It was determined using Eq. 2, as stated by Saheb and Babu'17), 18).

$$
T h_{r}=\frac{W_{t} \times 2}{4}
$$

A 7.92 $\mathrm{N}$ thrust was obtained as the required thrust to hover the quadcopter in the air. To calculate the produced thrust for the system three (3) components are selected.

1. Propeller 1045

2. Battery with capacity $3300 \mathrm{mAh}$ 3S/11.1 V and

3. $930 \mathrm{Kv}$ motor $[12,14]$. 
Eq. 3 is used to determine the thrust produced by the motor, $T_{m}$ in $\mathrm{N}$ [4].

$$
T_{m}=\sqrt[3]{2 \times \pi \times r_{p}^{2} \times \rho_{\text {air }} \times\left(P \times \eta_{h}\right)^{2}}
$$

Where $r_{p}$ is the radius of the propeller in $\mathrm{m}, \rho_{\text {air }}$ is the air density $1.225 \mathrm{~kg} / \mathrm{m}^{36}$ ), $\mathrm{P}$ is the power in $\mathrm{W}$ and $\eta_{\mathrm{h}}$ is the hovering efficiency. $\mathrm{P}$ is obtained from Eq. $4^{5)}$.

$$
P=k \times N^{p f}
$$

Where $\mathrm{k}$ is the propeller constant, $\mathrm{N}$ is the speed in revolutions per minute ((rpm) in thousands) and pf is the power factor. $\mathrm{N}$ is determined using Eq. 5, as stated by Huang et al. ${ }^{20)}$.

$$
N=K v \times V
$$

Where $\mathrm{Kv}$ represents the rpm per volt from the specification of the motor and $\mathrm{V}$ is the voltage supplied in $\mathrm{V}$, from the battery to the motor. $\mathrm{k}$ and pf for 1045 propeller values are 0.144 and 3.2 respectively ${ }^{20)}$. The produced thrust is $15.72 \mathrm{~N}$.

\subsection{Structural analysis FEA set up}

The 3D model was imported to ANSYS workbench. Thereafter the materials were selected and applied from the material library from ANSYS material database. The material used are Nylon 6 (PA6) for the arms and E-glass fibre for the frames ${ }^{2}$. The properties are given in Table (2) from the ANSYS engineering data base.

Table 2. Material properties

\begin{tabular}{|l|l|l|}
\hline \multicolumn{1}{|c|}{ Material } & Property & Value \\
\hline Nylon 6 (PA6) & & \\
\hline & Density & $1140 \mathrm{~kg} / \mathrm{m}^{3}$ \\
\hline & Young's modulus & $1060 \mathrm{MPa}$ \\
\hline & Poisson ratio & 0.35 \\
\hline & Bulk modulus & $1177.8 \mathrm{MPa}$ \\
\hline & Shear modulus & $392.59 \mathrm{MPa}$ \\
\hline & Tensile ultimate & $49.7 \mathrm{MPa}$ \\
\hline & strength & \\
\hline & Tensile yield strength & $43.1 \mathrm{MPa}$ \\
\hline & & \\
\hline & Density & $2660 \mathrm{~kg} / \mathrm{m}^{3}$ \\
\hline & Young’s modulus & $73000 \mathrm{MPa}$ \\
\hline & Poisson ratio & 0.22 \\
\hline & Bulk modulus & $43452 \mathrm{MPa}$ \\
\hline & Shear modulus & $29918 \mathrm{MPa}$ \\
\hline
\end{tabular}

The analysis was conducted in two phases; (i) Analysis of the complete frame and (ii) Analysis of single arm. Mesh was applied to both geometries separately. The mesh from frame structure is given in Fig. 2.

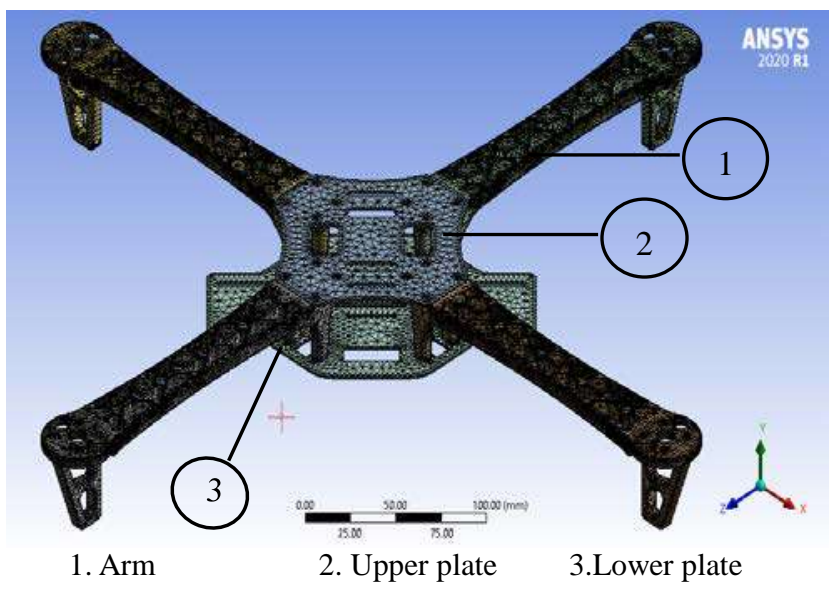

Fig. 2: Mesh results for frame structure

After setting the fixtures the loads were applied as depicted in Fig. 3 and analysis conducted.

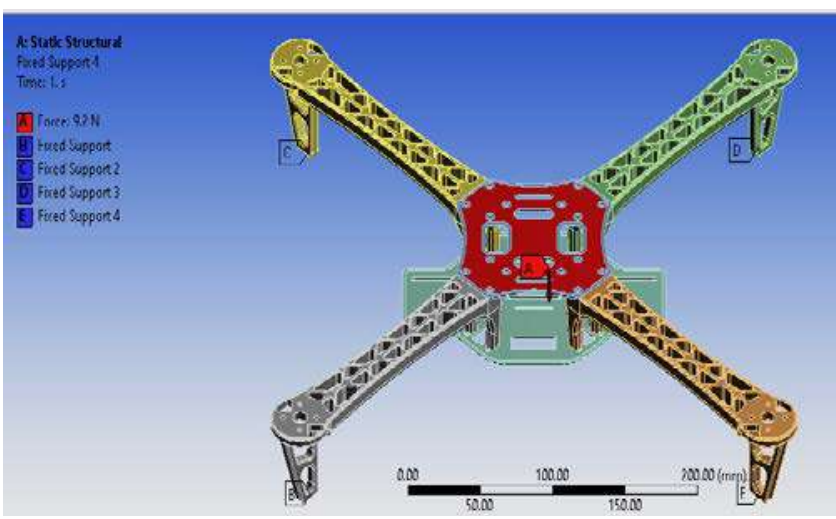

Fig. 3: Application of boundary conditions to frame structure

The same procedure is used for the single arm investigation as seen in Fig.4.

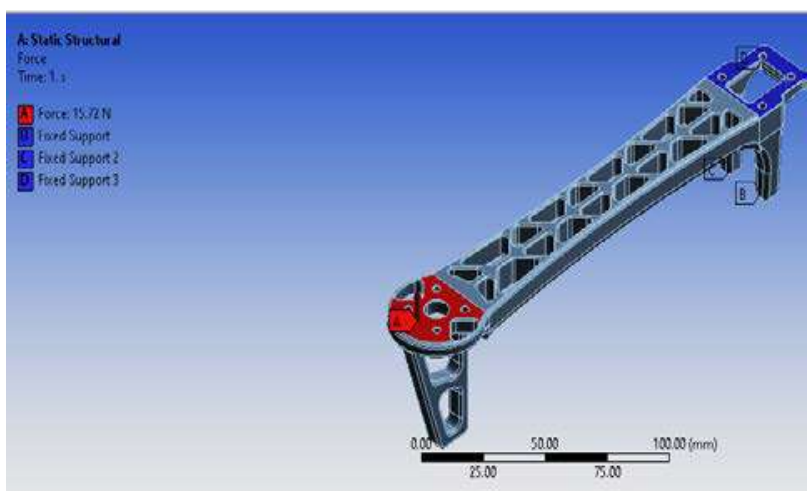

Fig 4: Application of boundary conditions to the arm

\subsection{CFD analysis set up}

Wind is considered the most challenging obstacle for drone deployment, which is why knowing the wind characteristic of the deployment area is of immense interest ${ }^{21)}$. Hopefully the study area where the quadcopter will be deployed is Bida, Niger State Nigeria which has relatively low wind speeds. A speed of $7 \mathrm{~m} / \mathrm{s}$ is suggested 
by Radiansyah, et al. ${ }^{22)}$ for wild life monitoring speed to be employed for UAVs, same will be adopted for the study since the drone is to be deployed for pest monitoring and control. Relatively low speeds is essential for proper monitoring of the site and bird detection while in operation.

ANSYS FLUENT was used for the analysis with only the external body excluding cavities and internal spaces considered $^{23)}$. The quadcopter was initially inserted in an enclosure and the body subtracted from the enclosure leaving the essential features of the body for study. Mesh was then applied to the structure for further study to be conducted.

For boundary conditions laminar flow option is selected for the analysis ${ }^{11)}$. The aerodynamic behaviour of the quadcopter moving at $0^{\circ}$ and $30^{\circ}$ inclination was investigated $^{11)}$.

\section{Results and Discussion}

The results are categorised into structural and flow simulation analyses based on the studies conducted.

\subsection{Structural analysis}

The maximum stress obtained on the complete frame subjected to $9.2 \mathrm{~N}$ load is $2.60 \mathrm{MPa}$ along with a strain of 0.0016 with a factor of safety value 15 . The stresses are more prevalent on the top plate at regions with holes as seen in Fig. 5. These areas are generally the stress concentration areas due to dimensional irregularities in the geometry of the structure. The areas where the arm joins the plates also has considerable stress recorded up to 1.21 MPa. The stresses might be lower since ductile materials (Nylon 6 PA6) are tougher than brittle (E-glass) ones.

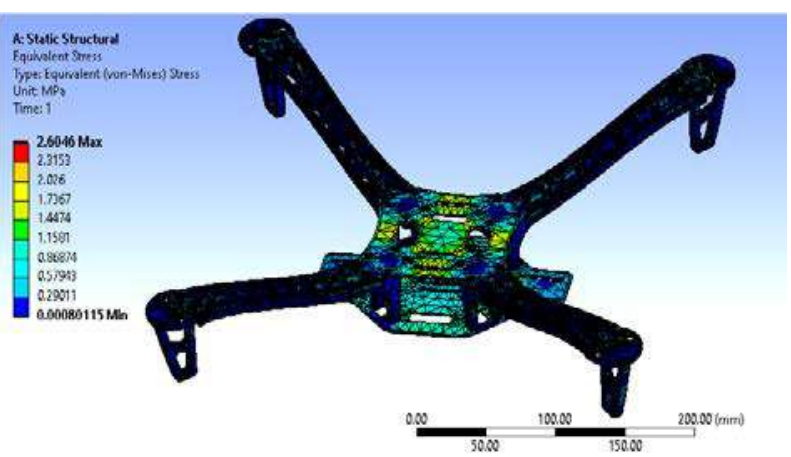

Fig. 5: Frame structure results for stress analysis

The minimum of $0.0008 \mathrm{MPa}$ however, is present at the mid regions of the arms towards the fixtures away from joint areas. The maximum deformation recorded is 0.97 $\mathrm{mm}$ as shown in Fig. 6. The deformation is maximum where the load was applied.

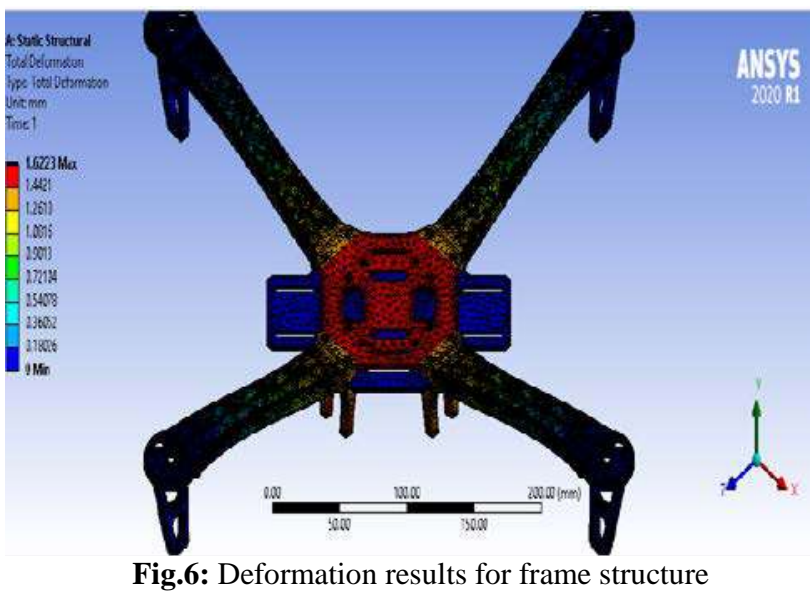

As for the arm investigation the stresses were spread across the length of the arm towards the fixtures ${ }^{24)}$ and range from 0.0015 to $39.13 \mathrm{MPa}$. As seen in Fig. 7.

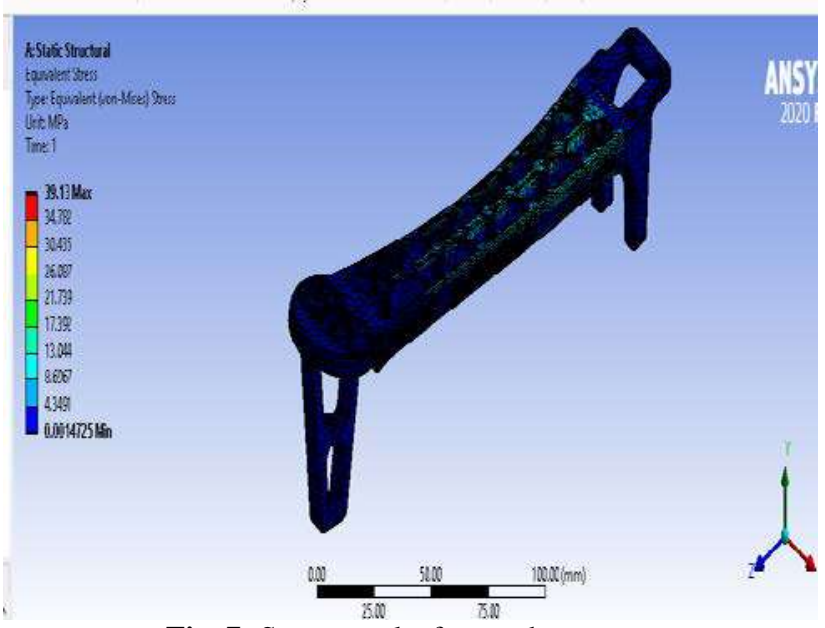

Fig. 7: Stress results for quadcopter arm

Both stresses are within the safe working stress of the components so design is safe ${ }^{2), 5), 6)}$. The stress concentration areas behave similar to those recorded in previous literature ${ }^{2), 24), 25), 26)}$. Singh, et al. ${ }^{2)}$ describes the maximum stresses on the quadcopter arms located towards the inner parts, where they are attached the plate.

\subsection{CFD analysis}

The drag and lift force obtained are $1.02 \mathrm{~N}$ and $0.41 \mathrm{~N}$ respectively for the $0^{\circ}$ flight configuration of the drone. The total pressure on the surface is determined to be 3.508 $\times 10^{-5} \mathrm{MPa}$ as shown in Fig. 8. The pressure is more prevalent on the arms in the same direction as the wind flow.

There is an increase in the drag force to $1.78 \mathrm{~N}$ as the quadcopter is tilted $30^{\circ}$. More of the arm structure is resisting the wind which results in the pressure increase. 


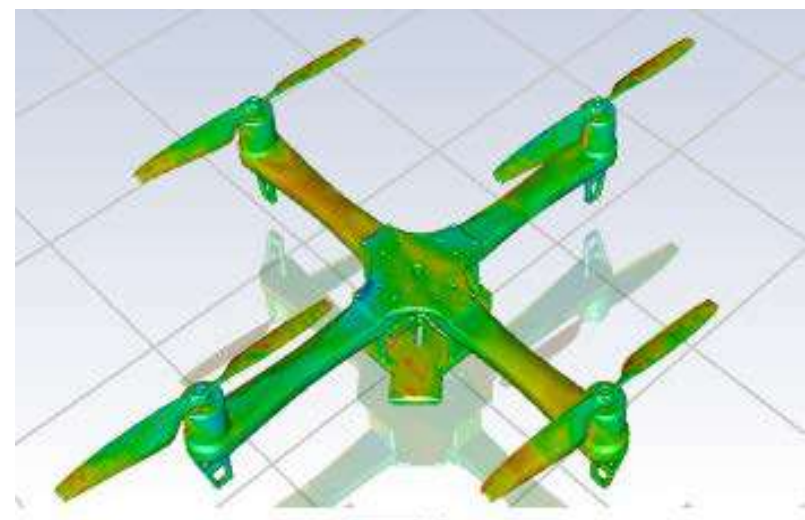

Fig. 8: Total surface pressure flow simulation result

The force becomes $-0.78 \mathrm{~N}$ as seen in Table 3 . The negative value insinuates a push downwards. This will necessitate expending more force to keep the drone hovering ${ }^{10), 28), 29)}$.

Table 3 CFD Results

\begin{tabular}{|l|l|l|l|l|}
\hline \multicolumn{1}{|c|}{$\mathbf{S} / \mathbf{N}$} & $\begin{array}{c}\text { Inclination } \\
\left({ }^{\circ}\right)\end{array}$ & $\begin{array}{c}\text { Drag } \\
(\mathbf{N})\end{array}$ & $\begin{array}{c}\text { Lift } \\
(\mathbf{N})\end{array}$ & $\begin{array}{c}\text { Pressure } \\
\left.\mathbf{( 1 0}^{-\mathbf{5}} \mathbf{M P a}\right)\end{array}$ \\
\hline 1. & 0 & 1.02 & 0.41 & 3.508 \\
\hline 2. & 30 & 1.78 & -0.78 & 3.689 \\
\hline
\end{tabular}

Also increased is the total pressure to $3.689 \times 10^{-5}$ $\mathrm{MPa}$. The pressure is present more in the geometry areas with sudden changes and sharp corners ${ }^{28)}$ as seen in Fig. 9. The most inclined motors facing the wind and the lower plate experience more of the increased pressure described.

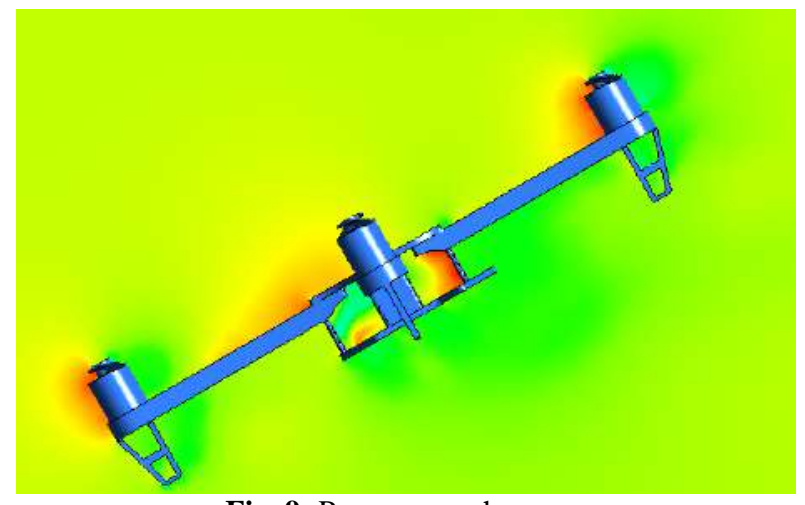

Fig. 9: Pressure on sharp corners

Carefully studying Fig. 10 shows flow lines in relatively straight undisturbed movement as opposed to Fig. 11 where the $30^{\circ}$ inclination is causing mild turbulence as depicted. This is what causes the high pressure and is responsible for aerodynamic resistance ${ }^{11)}$. Felismina et al. ${ }^{11)}$ further stated that such inclinations may cause recirculation that causes drastic decrease in lifting and drag force.

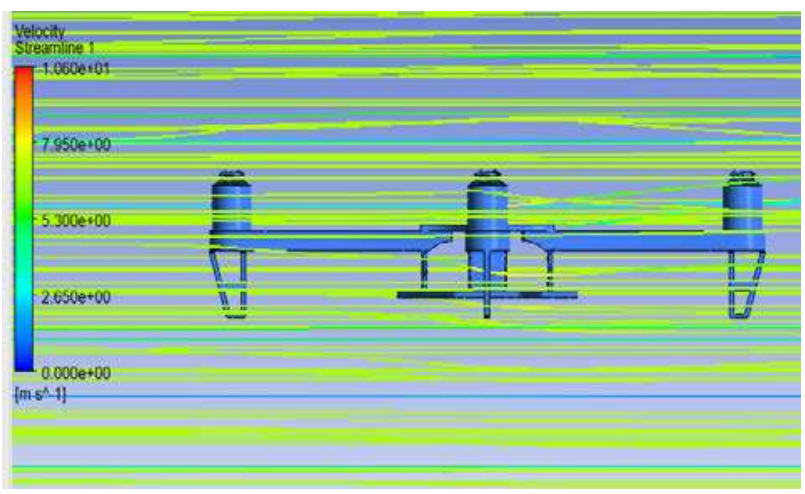

Fig. 10: Flow current lines on frame for $0^{\circ}$ inclination

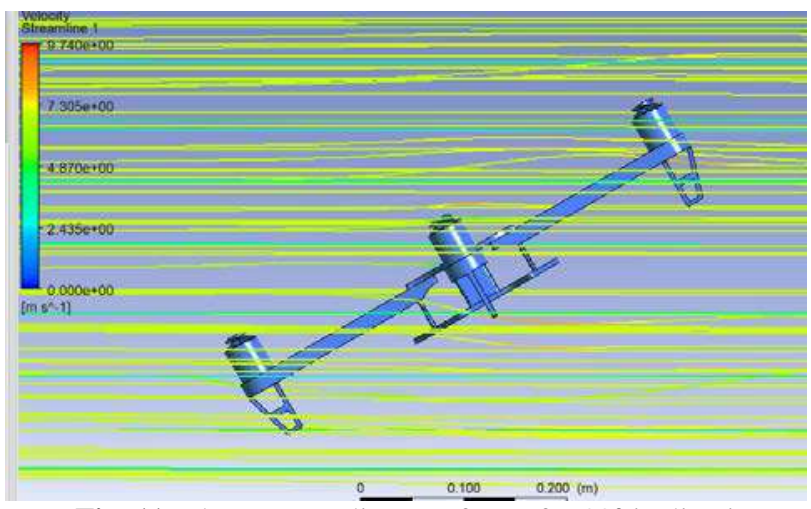

Fig. 11: Flow current lines on frame for $30^{\circ}$ inclination

\section{Conclusions}

The drone's structure selected to be deployed for bird control has been successfully analysed for suitability of purpose. The structure was modelled in SolidWorks and analysed using ANSYS Workbench simulation tools. Maximum stresses obtained are 18.51 and 39.13 MPa for the frame and arm structures respectively. The stress is well within safe working limits for the material, therefore safe for use. The CFD flow reveals a higher drag of $1.9 \mathrm{~N}$ during roll and pitch motions. Minimising those movement patterns will be incorporated in designing the flight mission during operation to save battery life when drone is deployed.

\section{References}

1) I. Sulaiman, A. Babawuya, O. Adedipe, B.A. Salihu, A.A. Aliyu, and A.G. Ibrahim, "A Review of Bird Pest Repellent Systems in Farms," $20201^{\text {st }}$ International Business Management Conference Wukari, 1-13 (2020).

2) R. Singh, R. Kumar, A. Mishra, and A. Agarwal, "Structural analysis of quadcopter frame," Materials Today Proceedings, 22 3320-3329 (2019).

3) R.F. Gordon, P. Kumar, and R. Ruff, "Simulating quadrotor dynamics using imported cad data," American Institute of Aeronautics and Astronautics, 1-7 (2013).

4) A. Yousefian, N. Yamamoto, "3D finite difference time domain simulation of microwave propagation in a coaxial cable” EVERGREEN Joint Journal of Novel 
Carbon Resource Sciences \& Green Asia Strategy, 5 (3) 1-11 (2018).

5) E. Kuantama, D. Craciun, and R. Tarca, "Quadcopter body frame model and analysis" Annals of the University of Oradea, 1, 71-74 (2016).

6) F. Ahmed, M.N. Zafar, and J.C. Mohanta, "Modeling and analysis of quadcopter F450 frame,” 2020 International Conference on Contemporary Computing and Applications, 196-201 (2020).

7) A.M. Halawa, B. Elhadidi, and S. Yoshida, "POD \& MLSM application on DU96-W180 wind turbine airfoil,” EVERGREEN Joint Journal of Novel Carbon Resource Sciences \& Green Asia Strategy, 4 (1) 3643 (2017).

8) A.M.M. Ismaiel, S.M. Metwalli, B.M.N. Elhadidi, and S. Yoshida, "Fatigue analysis of an optimised HAWT composite blade," EVERGREEN Joint Journal of Novel Carbon Resource Sciences \& Green Asia Strategy, 4 (3) 1-6 (2017).

9) M. Sherma, and M. Soni, “A musculoskeletal Finite Element Study of a unique and customised jaw joint prosthesis for the Asian populace," EVERGREEN Joint Journal of Novel Carbon Resource Sciences \& Green Asia Strategy, 7 (3) 351-358 (2020).

10) I. Omar, and Y. Shigeo, "Experimental and numerical studies of a horizontal axis wind turbine performance over a steep 2D hill.” EVERGREEN Joint Journal of Novel Carbon Resource Sciences \& Green Asia Strategy, 5 (3) 12-21 (2018).

11) R. Felismina, M. Silva, A. Mateus, and C. Malca, "Study on behaviour of a UAV with an applied seeder for agricultural practices". AIP Conference Proceedings, 1-15, (2017).

12) O.J. Al-zogphy, O.I. Khalil, and A.O. Elnady, "CFD analysis of quadcopter," The $4^{\text {th }}$ international undergraduate research conference, Egypt, 1-4 (2019).

13) N. Tenguria, N.D. Mittal, and S. Ahmed, "Review on horizontal axis wind turbine rotor design and optimisation,” Trends in Applied Sciences Research, 6 309-344 (2011).

14) R. Axisa, M. Muscat, T. Sant, and R.N. Farrugia, "Structural assessment of a lattice tower for a small, multi-bladed wind turbine," International Journal of Energy Environmental Engineering, 8 343-358 (2017).

15) S. Çaşka, K. Gök, M. Aydin, and I. Özdemir, "Finite element method based structural analysis of quadcopter UAV chassis produced with 3D printer," Journal of Scientific Reports, 44 24-32 (2020).

16) M. Biezyski, R. Sehab, J.F. Whichborne, G. Krebs, and P. Luk, "Multirotor sizing methodology with flight time estimation," Journal of Advanced Transportation, 2020 1-14 (2020).

17) S.H. Saheb, and G.H. Babu, "Design and Analysis of Light Weight Agriculture Robot," Global Journal of Researches in Engineering," 17 (6) 1-19 (2017).
18) P.V. Sawalakhe, and J.A. Shaaikh, "Simulation and analysis of a quadcopter UAV while landing," International Journal of Recent Technology and Engineering, 8 (6), 672-680 (2020).

19) L.N. Aswin, P. Rajasekaran, S.K. Radhakrishnan, and K.S. Krishnan, "Design and structural analysis for an autonomous UAV system consisting of slave MAVs with obstacle detection capability guided by a master UAV using swarm control," International Organization of Scientific Research (IOSR) Journal of Electronics and Communication Engineering, 6 (2), 1-10 (2013).

20) C.S. Huang, F.Y.C. Albert, C.K. Ang, J.T. Dwee, and C.K. Chan, "Theoretical development and study of takeoff constraint thrust equation for a drone," Institute of Electrical and Electronics Engineers (IEEE), 1-5 (2017).

21) S.S. Dol, “Aerodynamic optimisation of unmanned aerial vehicle for offshore search and rescue (SAR) operation,” Materials Science and Engineering, 715 (2020) 1-6 (2020).

22) S. Radiansyah, M.D. Kusrini, and L.B. Prasetyo, "Quadcopter applications for wildlife monitoring," Institute of physics (IOP) Conference Series: Earth and Environmental Science, 54 (2017) 1-8 (2017).

23) D. A. Wulandari, M. Akmal, Y. Gunawan, Nasruddin, "Cooling improvement of the IT rack by layout rearrangement of the a2 class data center room: A simulation study", EVERGREEN Joint Journal of Novel Carbon Resource Sciences \& Green Asia Strategy, 7 (4) 489-499 (2020).

24) B. Patel, R.P. Sukhija, and R.P.S. Kumar, "Structural Analysis of arm of multicopter with various loads," International Journal of Emerging Technology and Advanced Engineering, 8 (4) 215-223 (2018).

25) A.V. Javir, K. Pawar, S. Dhudum, N. Patale, and S. Patil, "Design, Analysis and Fabrication of Quadcopter," Journal of Advance Research in Mechanical and Civil Engineering, 2 (3) 16-27 (2015).

26) P. Wei, Z. Yang, and Q.Wang, "The design of quadcopter frame based on finite element analysis," 3rd International Conference on Mechatronics, Robotics and Automation (ICMRA 2015), 1353-1356 (2015).

27) E. Baris, C.P. Britcher, and G. Altamirano, "Wind tunnel testing of static and dynamic aerodynamic characteristics of a quadcopter," American Institute of Aeronautics and Astronautics, 1-11 (2019).

28) H.I. Muhammad, A. Rahman, N.B. Prihantini, Deendarlianto, Nasruddin, "The application of polydispersed flow on rectangular airlift photobioreactor mixing performance” EVERGREEN Joint Journal of Novel Carbon Resource Sciences \& Green Asia Strategy, 7 (4) 571-579 (2020). 